\title{
48. A New Disease of Hop Due to a Bacterium
}

\author{
By Isamu Stow
}

Brewing Scientific Research Institute, Meguro Laboratory, Tokyo

(Comm. by H. Kihara, M.J.A., March 12, 1954)

Within the past few years, an epidemic disease of hop, which is different from Downy Mildew or Crown Gall, has broken out in many hop gardens in Japan excepting the Hokkaido province. ${ }^{1)}$ The appearance and symptoms of the present disease can be classified into the following 4 types.

i) “ Cauliflower-like" type :

Hundreds of densely crowded buds massed on the surface of somewhat tumorously swollen tissue of the root-stock, so that it looked like a cauliflower (Fig. 1). The disease of this type usually occurs in late April or early May, and the farmers are often unaware of it for a long time as it is hidden under the soil.

ii) "Witches'broom " type :

The crown of rootstock was covered with numerous thin, or abnormally shrunken shoots already forming secondary buds or short degenerated branches on the nodes. So it

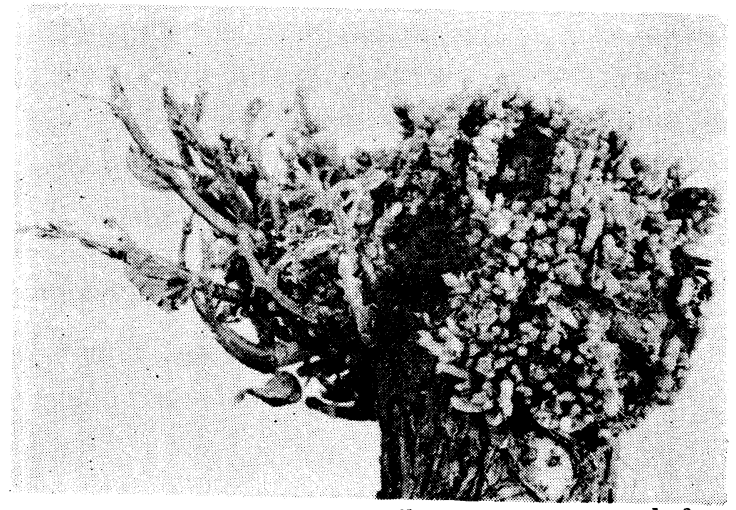

Fig. 1. A "Cauliflower-like" type root-stock from Hosina, Kami-Takai County, Nagano Prefecture; photographed May 27, 1953. On the right part, densely crowded adventitious buds arise from somewhat tumourously swollen tissues. On the left, several abnormal shoots arise which had short internodes and

\section{looked like a broom degenerated tips.}

turned upside-down. The thin and healthy shoots grow a meter long, but the abnormal ones never exceed $30 \mathrm{~cm}$., because their tips wilt to death sooner or later.

The majority of the case of "Witches'-broom " type disease may be induced from " Cauliflower-like" type. They usually are found in late May. Sometimes, a somewhat different type of this disease can be found in late summer, and the writer got some specimens even in the middle of October (Fig. 2).

1) The historical investigations and general observations in the field were carried out by Sakai and Uéhara. 
As to the latter case, it has not developed from the " Cauliflower-

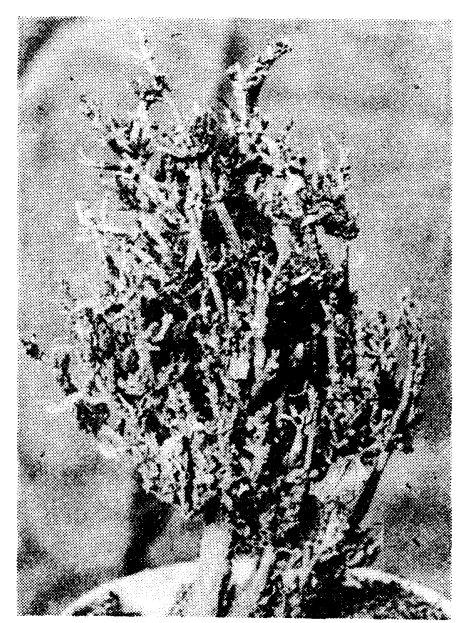

Fig. 2. A “Witches'-broom" type material from Naka-Minowa, Kami-Ina County, Nagano Prefecture. Photographed by Miss K. Ihara, mid-October, 1953. In the laboratory: Many abnormal branches of primary, secondary and tertiary growth developed on the short degenerated bines, differing from tumorous swellings of the rootstock.

Instances of the "Whip-shaped" type disease are found usually in late May, and never in other months.

iv) " Dry Tip-rot" type :

When the hop bine nearly reached the top wire of the garden, the tip of the main bine died and dried up suddenly without having shown any symptom of the disease till that time. Then the lateral buds of the upper nodes promptly began to develop and grow healthily into vigorous branches so the growth of the bine was recovered. The disease of this type occurs in vigorous, well grown plants in a well fertilized farm, and never in the poor bines in a lightly fertilized one. It can be found only in the middle of June, and never in other months.

It is generally believed by the farmers that the present disease happened in 1940 for the first time. But the writer can suppose that it may have occasionally happened even in the early times of hop cultivation in Japan, ${ }^{2}$ and that it broke out somewhat epidemically

2) One can find a photograph and a short description of a hop disease, which closely resembles the present one, in Shinohara's notes arranged by Teragaki and Sakai (1952). 
in 1940 and 1941 in Nagano prefecture. From that time till 1951, there are available no reports of its occurrence.

On the other hand, the above described symptoms so closely resemble, in many points, those of the "Small Hop" disease after Salmon and Ware (1932), that these two diseases seem to be the same one.

At first, it was considered to be a virus or a physiological disease, but that view proved untenable. Then anatomical investigations were undertaken. Freehand sections of fresh material were stained in lactic blue. No hypha of a fungus was found, but some amorphous masses of a mucous substance stained blue were observed in the tissues where no sieve tube existed. From these facts, it was considered that the mucous mass may be a bacterial mass, though it could not be ascertained with surety on account of the inferiority of the microscope employed at that time.

When the specimens of "Witches'-broom " and "Whip-shaped" types were set in water in a vase placed on the desk, the tips of them wilted fairly soon and died to dry up the next day. This fact seems to indicate that there might be some abnormality in the vessels. Then cross sections of the diseased portion and its lower part were made. The degeneration of vessels was found in marked degree, as expected. The number of the xylem bundles had diminished to less than normal, the development of the vessels was low, and some of the primary-vessels had been destroyed (Figs. 3 and 4). Moreover, sometimes not only the small primary vessels, but also the large secondary ones were filled up entirely closed with an amorphous substance which became brown in a day. This substance which filled the vessels might not be resin, but it could not

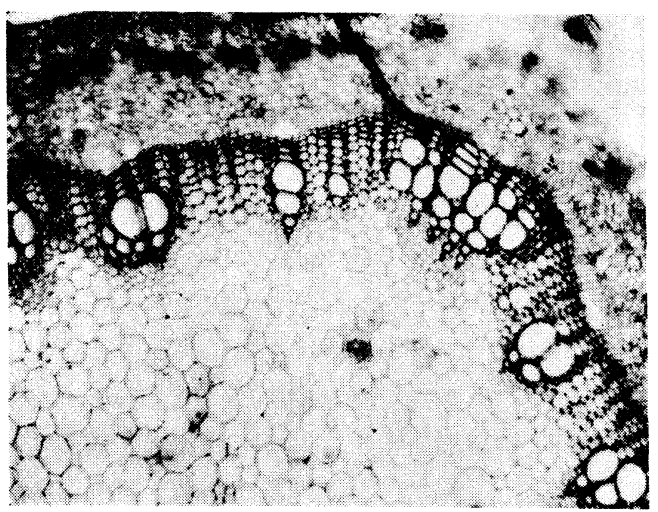

Fig. 3. Photomicrograph, $\times$ ca. 80 . Freehand section of normal internode of a shoot just above the first expanded leaves. Stained in safranin and gentian violet, mounted in water. The bundles and mechanical structure developed in some degree. The secondary vessels and pith hollow had not yet developed. have, up to today, been ascertained whether it was a gummy substance or a phenolic one.

The noticeable fact is that there were sometimes found some short, rod-shaped minute bodies stained in safranin, fuchsin $\mathrm{S}$ or crystal violet, in the plug substance which filled the vessels. These 
minute bodies seemed to be a rod becterium from their shape, size

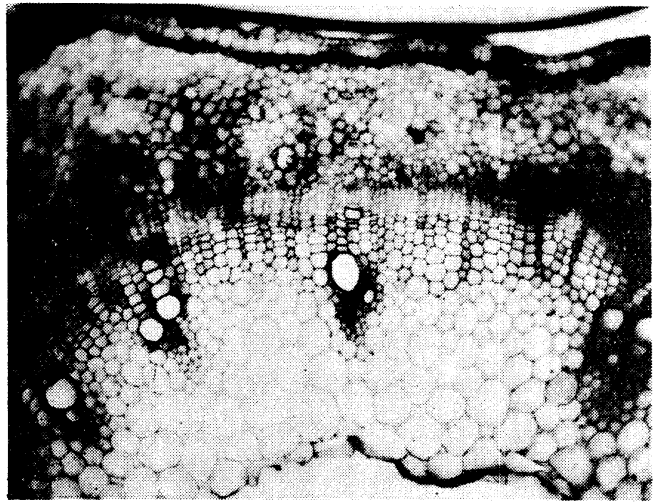

Fig. 4. Photomicrograph, $\times c a$. 80. Freehand section of the internode of a shoot of the "Whip-shaped" type material; just above the 1st expanded leaves. Stained in safranin and gentian violet, mounted in water. Only the diminutive bundles and mechanical structure were visible. Sometimes the degeneration of the primary vessels had taken place. A large pith hollow appeared. and the staining reactions.

When the surface of a longitudinal cutting of the fresh "Dry Tip-rot" material was treated with a dilute crystal violet aqueous solution, the dead or diseased portion of the tip was stained into deep violet. Apart from the tip, a second small spot was often found in the pith just above the next node. It could be observed even with an ordinary magnifying glass that these two spots were connected by some of threads, stained in violet as were also the spots. These stained portions could not be considered to be lignified or suberized membranes.

Next, preparations of the freehand sections of the materials fixed with chromo-acetic-osmic solution and stained with dyes, were observed under the microscope. In the rot-portion of the tip only dead cells exist. In the cortex of the successive portions to the tip-rot the dead tissue contacts directly with the living tissue and the dead and living cells never exist mixed together. But, in the pith, some dead cells exist among the living cells. In such a portion, some of the intercellular spaces were filled with a somewhat mucous substance, in which could be discerned a number of

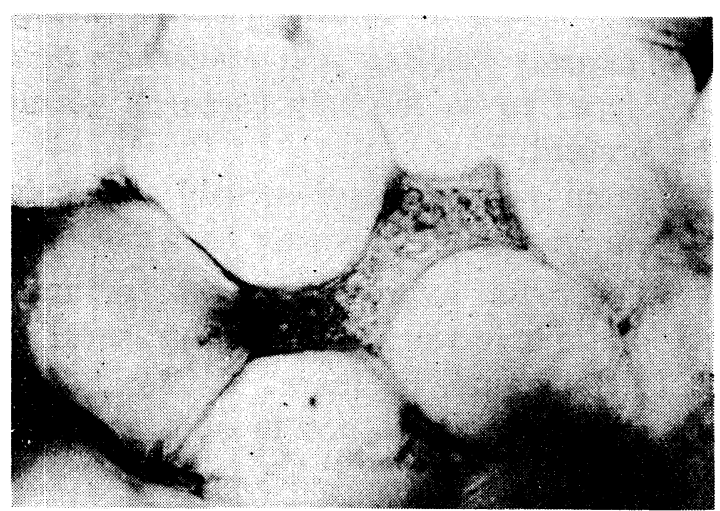

Fig. 5. Photomicrograph of a freehand section of the "Dry Tip-rot" type material, nearly top portion of the living tissues in contact with the rot-tissue, $\times c a .1000$. Fixed with chromo-acetic-osmic solution, stained in crystal violet, mounted in balsam. A mueous substance with minute bacteria-like bodies, filled the intercellular space.

stained minute bodies (Fig. 5). Similar ones were also observed in some of the intercellular spaces of the connecting threads. 
As a result of the observations above described, especially from the anatomical points of view, it is very reasonable to assume that the minute bodies in the plugged vessels and the intercellular spaces might be a bacterium, and then that the present disease would be a bacterial one. Therefore, the isolation was tried of bacteria from some of the "Witches'-broom" type materials, because none of the other types was obtainable in late July.3.

From many bacterial colonies on the plate cultures with bouillon-pepton agar medium, four strains were distinguished. Inoculation tests were the next logical procedure to ascertain whether or not these represented strains were the real disease germ of the present disease. ${ }^{4}$ At time passed, before a preliminary test actually took place in late August, the conditions became unsuitable for the inoculation; the hop bines were matured and the weather was too hot. In spite of such unfavourable conditions, two positive results were obtained. The "Dry Tip-rot" type disease developed, when a strain of the bacteria isolated from the "Witches'-broom" type material was inoculated to the tip of about 1.5 meter long healthy shoots. It is a noteworthy fact that the "Dry Tip-rot" type disease naturally happens only in the middle of June.

Though the identification of the bacterium is not yet completed, the writer can say that it may be Aplanobacter. It closely resembles Aplanobacter insidiosum, and to a certain degree, Aplanobacter fasciens. But some different characters can be recognized between the new one and even Aplanobacter insidiosum. Also it differs from Aplanobacter fasciens, and Bacterium tumefasciens which have been considered to be the only bacterial germ of the hop disease up to the present.

From the results described above, it is natural to suppose the present disease of hop may be a new bacterial one.

The writer expresses his hearty thanks to Prof. N. Hiratsuka for his kind suggestions. He also gratefully expresses his indebtedness to T. Hamaguti, K. Ihara, Y. Mori, M. Sakai, and Y. Uĕhara for their valuable assistance in each assigned part of the study.

\section{Summary}

i) In Nagano and Yamagata prefectures a disease of hop has occurred in the last few years which is different from the usual Downy Mildew or the Crown Gall disease. It was observed from the physiological and pathological points of view.

3) The isolation of bacteria from the materials was carried out by Miss K. Ihara.

4) The inoculation tests were carried out by T. Hamaguti and Y. Mori. 
ii) Considerable degeneration and diminution of the vessels take place in a somewhat lower part of the diseased shoot of the "Witches'-broom" type and "Whip-shaped" materials. The vessels of such materials were often plugged with some mucous substance.

iii) Rod bacterium-like minute bodies were observed in some of the plugged vessels, and in the intercellular spaces of the diseased tissues.

iv) Several strains of bacteria were isolated from "Witches'broom" type materials.

v) Two positive results were obtained in the preliminary inoculation tests with one of the strains of the isolated bacteria.

\section{References}

Elliot, C.: Manual of bacterial plant pathogens. Mass. U.S.A. (1951).

Salmon, E. S. and Ware, W. M.: The small hop disease. Journ. of the SouthEastern Agr. Coll. Wye, 30, 22-26 (1932). 